Article

\title{
Performance of Commercially Available Supercapacitors
}

\author{
Mazen Yassine * and Drazen Fabris * \\ Mechanical Engineering Department, Santa Clara University, Santa Clara, CA 95053, USA \\ * Correspondence: myassine@scu.edu (M.Y.); dfabris@scu.edu (D.F.)
}

Received: 17 July 2017; Accepted: 29 August 2017; Published: 5 September 2017

\begin{abstract}
High energy density storage device exhibiting a reliable lifecycle is needed in the 21st century. Hence, energy storage research is critical for reducing energy consumption. Supercapacitors exhibit such characteristics via interfacial ion electrosorption and fast redox reactions. They are a feasible solution for transportation applications, among others, due to their superb characteristics. In this paper, we provide a background on supercapacitors, review public data on commercially available supercapacitors for performance characteristics, and finally summarize their performance in terms of energy density, equivalent series resistance, and device time consistency.
\end{abstract}

Keywords: supercapacitors; cell capacitance; power density; electric vehicles; energy density; equivalent series resistance; operating voltage; time constant

\section{Introduction}

Ongoing energy sustainability efforts and the worldwide energy resources depletion have accelerated the efforts in expanding and refining energy efficient storage devices (ESDs) [1-3]. Supercapacitors (SCs) are poised to play a focal part in our future, and have been the subject of intense study. SCs are power-dense components suited for energy shuttling applications such as transportation (subways, buses, and elevators), intermittent generators (wind farms), and smart grids due to their fast charge propagation $[4,5]$.

They are prime candidates to bridge the power performance gap between capacitors and batteries. SCs are high power density energy storage devices (ESDs) that store energy electrostatically by polarizing an electrolytic solution. They utilize high surface area electrode materials $\left(3000 \mathrm{~m}^{2} / \mathrm{g}\right)$ and thin electrolytic dielectrics to attain capacitances greater than ordinary capacitors. As such, SCs are able to reach higher energy densities while still retaining the high power density characteristic of typical capacitors [6,7].

Their key performing factors are specific capacitance, energy density, power density, and cyclical stability. They consist of two electrolyte-immersed electrodes and a high-porosity thin separator that inhibits the charge from traversing across electrodes of opposing polarity. The electrolytes are carefully selected to reduce the internal resistance of the SC. Activated carbon was the first electrode material of choice. Carbon has high conductivity, porosity, and specific area properties. SCs are created to provide power bursts in seconds over thousands of cycles [8,9].

In this paper, we review the state and performance of commercially available SCs. In addition, we focus on performance characteristics, and discuss SCs' salient role as energy storage enhancers. Furthermore, we comment on the present and future application prospects of these devices.

\section{History}

Electrochemical capacitors were first introduced in the 1800s. In the 1890s, C. Pollak discovered that an oxide layer on an aluminum anode was stable in a neutral or alkaline solution, and accordingly 
was granted a patent in 1897 for a borax electrolyte aluminum capacitor. In 1957, Howard Becker, a General Electric engineer, submitted a patent (US2800616A) titled "Low Voltage Electrolytic Capacitor", which is a two-terminal charge storage device [10]. His work was based on experimenting with porous carbon electrodes for fuel cells and rechargeable batteries. Becker believed that the energy was stored in a form of a charge in the carbon pores, similar to electrolytic capacitors.

While experimenting with fuel cell designs in 1966, Standard Oil of Ohio, Inc. (SOHIO) engineers developed a different form of the capacitor. It was NEC, Inc. (Tokyo, Japan) that coined and brought to the forefront the "supercapacitor" in 1971, to serve as a backup power device for computer memory applications [11]. Since then, SCs have advanced and are now capable of storing higher charges. Some electrochemical series capacitors operate at $600 \mathrm{~V}$ and above, which make them suitable for power quality and intermittent, renewable fluctuation suppression applications.

\section{Background}

Ideal capacitors $\left(C=\varepsilon_{0} A / d\right)$ are characterized by a single constant capacitance, which is the ratio of the electric charge on each conductor to the potential difference between them $\left(E=Q / \varepsilon_{0} V\right)$. The energy is stored by accumulating positive and negative charges split via an insulating dielectric. The stored quantity can be enhanced by either increasing the capacitance or the voltage, which is limited by the dielectric strength. The capacitance can be increased by expanding the plate's area, increasing the electric permittivity, or decreasing the plates distance.

SCs differ from electrolytic capacitors in that the energy is not delivered via redox reactions; thus, employing anode and cathode terminology would be inaccurate. Instead, they incorporate thick surface area electrodes and thinner dielectrics, reducing the distance between the electrodes. This yields capacitance and energy increase by keeping low equivalent series resistance (ESR) characteristics (ESR is a physical value that represents Ohmic losses). SCs have advantages over batteries and fuel cells, including higher power density, shorter charging times, and a longer lifecycle [12,13]. The stored energy depends on electrostatic charges, as well as electrolyte ions that move towards the electrode surface with the opposing polarity. This is a physical phenomenon rather than a chemical reaction and is highly reversible. The metallic plates are coated with a porous substance such as activated charcoal, and immersed in an electrolyte, resulting in a larger area to store a higher charge [14]. The electrolyte-soaked plates are separated by a thin insulator. Opposing charges are formed on either side of the separator when the plates are charged, thus creating an electric double-layer. Hence, another name for SCs is electric double-layer capacitors (EDLC). Figure 1 shows the capacitance and the volume of commercially available devices. The total capacitance is attributed to the carbon's specific capacitance. The proportional linearity is dependent on the surface area of the overlapping plates and the packing efficiency of the individual designs.

To determine current performance characteristics, data were collected from device manufacturers. When available, the data are compared in like quantities. Basic performance characteristics are presented, allowing for the evaluation of performance variation and general trends. The data were collected (see Table 1) from publicly, commercially available products sourced from their companies website: APowerCap, Asahi Glass, BatScap, Fuji, Ioxus, JSR Micro, LS Mtron, Maxwell, NessCap, Panasonic, PowerStor, Skeleton, VinaTech, and Yunasko. 


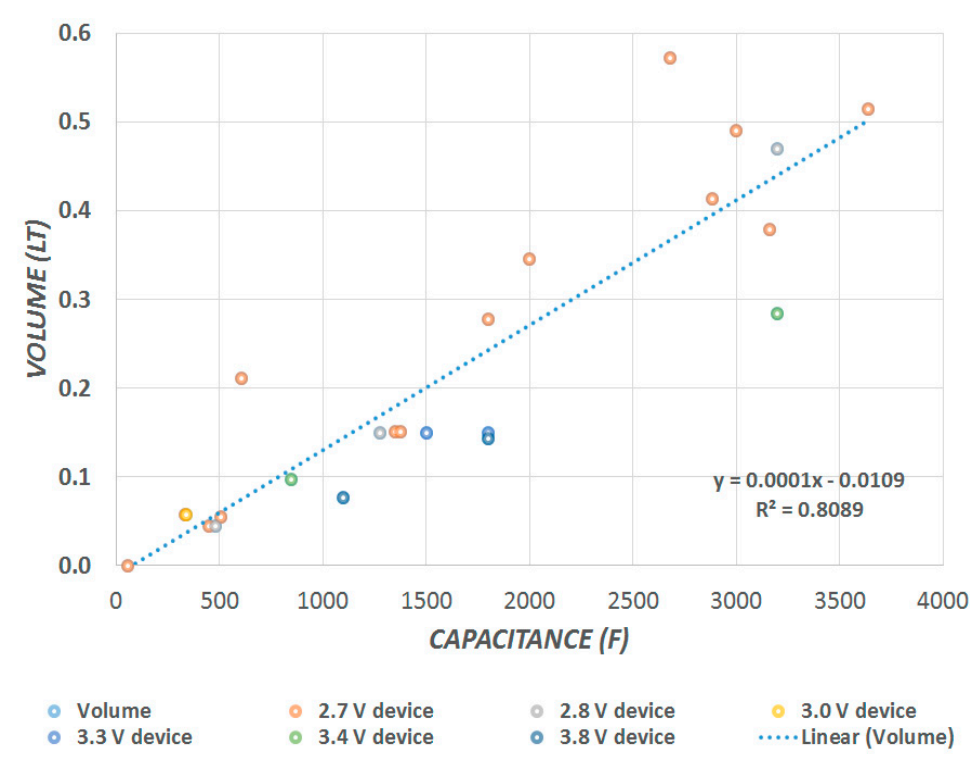

Figure 1. Volume vs. capacitance, exhibiting linear characteristics.

Table 1. Commercially available supercapacitor (SC) properties.

\begin{tabular}{cccc}
\hline Manufacturer & Voltage (V) & Capacitance (F) & ESR (m) $)$ \\
\hline APowerCap & 2.70 & 55 & - \\
APowerCap & 2.70 & 450 & - \\
Asahi Glass & 2.70 & 1375 & 2.50 \\
BatScap & 2.70 & 2680 & 0.20 \\
Fuji & 3.80 & 1800 & 1.50 \\
Ioxus & 2.70 & 3000 & 0.45 \\
Ioxus & 2.70 & 2000 & 0.54 \\
JSR Micro & 3.80 & 1100 & 1.15 \\
JSR Micro & 3.80 & 2300 & 0.77 \\
LS Mtron & 2.80 & 3200 & 0.25 \\
Maxwell & 2.70 & 2885 & 0.38 \\
Maxwell & 2.70 & 605 & 0.90 \\
NessCap & 2.70 & 1800 & 0.55 \\
NessCap & 2.70 & 3640 & 0.30 \\
NessCap & 2.70 & 3160 & 0.40 \\
Panasonic & 2.30 & 0.10 & 0.08 \\
Panasonic & 5.50 & 50 & 0.08 \\
PowerStor & 2.50 & 2.20 & 4.57 \\
PowerStor & 16.20 & 65 & 7.00 \\
Skeleton & 3.40 & 3200 & 0.47 \\
Skeleton & 3.40 & 850 & 0.80 \\
VinaTech & 2.70 & 336 & 3.50 \\
VinaTech & 3.00 & 342 & 6.60 \\
Yunasko & 2.70 & 510 & 0.90 \\
Yunasko & 2.75 & 480 & 0.25 \\
Yunasko & 2.75 & 1275 & 0.11 \\
Yunasko & 2.70 & 7200 & 1.40 \\
Yunasko & 2.70 & 5200 & 1.50 \\
\hline
\end{tabular}

Figure 1 shows that the capacitance is linearly proportional to the volume. SCs store energy in an electric field, which is generated between two opposing charged particles when they are separated. Thus, when an electromotive force is applied across the metallic plates, a charge causes the electrode to attract ions of the opposite charge. Hence, each carbon electrode ends up having a charge coating its surface, in effect creating two capacitors in series, one at each electrode. The total capacitance depends 
on the packing density of the plates and carbon electrodes, and is hence directly proportional to the volume, while it is independent of the voltage.

\section{Power Density}

In comparison with typical electrolytic capacitors and batteries, SCs are energy storage devices that concurrently offer high power and energy. SCs' maximum power $\left(P_{\operatorname{Max}}=0.25 V_{\operatorname{Max}}^{2} \times E S R\right)$ is determined by the maximum voltage $\left(V_{\mathrm{Max}}\right)$ and $E S R$. The stored energy is due to the activated carbon high surface area electrode material and short charge separation distance caused by the interface opposite charges between the electrode and electrolyte. SCs' power density is governed by the energy that is delivered per unit time. The power density is highest when the ESR and the load are matched.

The Ragone plot in Figure 2 presents energy storage capacity as a power output function by comparing the performance of different energy storage devices [15]. A typical Ragone plot shows discharged energy (Watt-hours) versus discharged power. The main idea is that the electrical current charging or discharging an energy storage device has to flow through both its internal resistance and the load resistance. This provides a useful method of comparing various energy storage systems. However, it does not provide insight into the actual obtainable power from the SC.

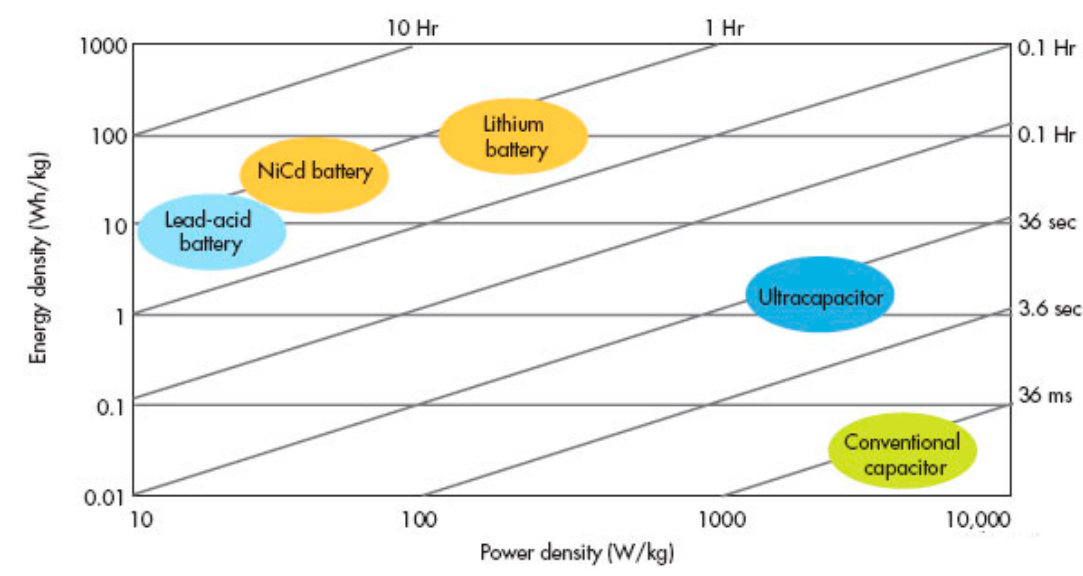

Figure 2. Ragone plot for various energy storage devices (ESDs), with diagonal discharge time (Source: ElectronicDesign.com, 15 November 2007).

\section{Energy Density}

Energy density is the quantity stored in an SC per unit mass. It can be calculated by integrating the $C-V$ curve that is generated from cyclic voltammetry. The energy densities of various storage devices are shown versus the power densities in Figure 2. It characterizes the SC in comparison to ESDs, with the horizontal axis representing power density, and the vertical axis representing energy density. The energy density can be enhanced by varying the voltage or the capacitance. In spite of having larger capacitances than typical capacitors, SCs lack the energy densities in comparison to lithium-ion batteries and fuel cells [16,17]. The energy density of Li-ion cells is in the $80-150 \mathrm{Wh} / \mathrm{kg}$ range, while compressed hydrogen has an energy density of $39,444 \mathrm{Wh} / \mathrm{kg}$.

\section{Classification}

SCs can be grouped into three classes: electrical double-layer capacitors (EDLCs) with activated carbon electrodes with a higher electrostatic double-layer capacitance than pseudo-capacitance; pseudo-capacitors based on the electrochemical redox method of charge storage with transition metal oxide or conducting polymer electrodes with a high amount of pseudo-capacitance; and hybrid capacitors with asymmetric electrodes which exhibit mostly electrostatic and the other electrochemical 
capacitance, such as lithium-ion capacitors [18,19]. These are non-faradaic (charges are distributed on surfaces), faradaic (electrode and electrolyte charge transfer), and a blend of the two.

The SC term has been used to describe the combination of electrodes that are catalyzed with ruthenium $\left(\mathrm{RuO}_{2}\right)$, iridium $\left(\mathrm{IrO}_{2}\right)$, iron $\left(\mathrm{Fe}_{3} \mathrm{O}_{4}\right)$, manganese $\left(\mathrm{MnO}_{2}\right)$, or titanium sulfide $\left(\mathrm{TiS}_{2}\right)$, generating strong faradaic combined with low resistance [20,21]. The quasi two-dimensional $\mathrm{RuO}_{2}$ introduces a redox couple between two ruthenium valence states, yielding higher static capacitance for the carbon electrodes that are associated with a lower time constant $(\tau=\mathrm{RC})$.

Their charge-discharge rate is limited by the electrodes' heat tolerance. As such, they are able to achieve higher energy densities while maintaining the high power density characteristic of typical capacitors. On the other hand, pseudo-capacitors are based on electrode charge storage supplemented by reversible faradaic electrochemical redox surface processes. This is achieved via electrosorption, reduction-oxidation reactions, and intercalation processes termed pseudo-capacitance. These faradaic processes permit pseudo-capacitors to attain greater capacitances and energy densities than EDLCs.

The main materials in pseudo-capacitors are oxides such as ruthenium $(\mathrm{Ru})$ and manganese (Mn). Unlike EDLCs, pseudo-capacitor has a chemical reaction at the electrode whereas the EDLCs charge is stored electrostatically without ions and the electrode interaction. Metal oxides and conducting polymers are the two widely used materials in pseudo-capacitors. Pseudo-capacitance and EDLC combine to create SCs' capacitance value. Pseudo-capacitance may be higher by a factor of 100 compared to an EDLC with the same electrode surface [22,23].

\section{Equivalent Circuit}

It is practical to represent the SC by a simplified circuit model. Figure 3 depicts the circuit representation, where the capacitance $C$, series resistance $R_{S}$ (also known as the equivalent series resistance $(E S R)$ ), parallel resistance $R_{p}$, and series inductance $L$ are the ideal components of equivalent insulation resistance (ESL) [24]. In conventional capacitors, $R_{p}>>R_{s}$, hence $R_{p}$ can be neglected. SCs behave non-ideally, due to the porous material used in forming the electrodes, which cause the resistance and capacitance to be distributed such that it resembles having a transmission line characteristic. Thus, it is not unusual to simplify the circuit further to an $R_{i} C_{i}$ system, including $R_{i}$, the internal resistance, and $\mathrm{C}_{\mathrm{i}}$, the electrostatic capacitances of the activated carbons.

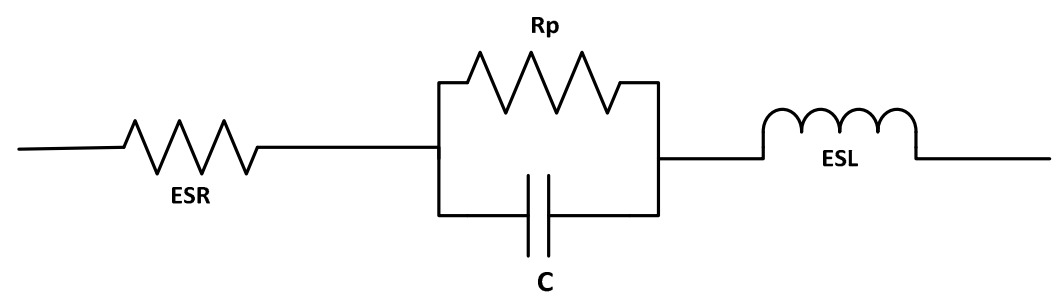

Figure 3. SC simplified circuit model [24].

The SC voltage profile has resistive and capacitive components. Manufacturers define the ESR, which depends on cell size, as the measured impedance at the resonant frequency, or the ESR calculated value at some $\mathrm{AC}$ frequency (e.g., $100 \mathrm{kHz}$ ). The resistance is made of ionic inertia, electrolyte conductivity, impurities, and electronic parts. The conductor ohmic resistance and carbon particles contribute to the electronic part, whereas the mobility of electrolyte ions contributes to the ionic part. It is not just the electrodes, electrolyte, surface characteristics, and packing that influence the ESR, but also the manufacturing capabilities. Hence, each manufacturer has its proprietary manufacturing method that is kept secret to maintain a competitive edge. Thus, equally important to the laboratory research, it is the actual development of the device that determines the true ESR.

The ESR and capacitance vary over the frequency spectrum, and are usually measured with a bridge, LCR meter, or impedance spectrum analyzer near $1.0 \mathrm{~V}$ [25]. The required charge time is 
dependent on the time constant values. The stored energy is a function of the electrode and electrolyte surface, the ions size, and the electrolyte decomposition voltage level. Figure 4 shows that the ESR is inversely proportional to the device capacitance $\left(E S R \propto 1 /\right.$ cap $\left.^{0.6}\right)$. We identified that there is a trend of decreasing ESR with increasing capacitance; a trend line is indicated through the data. Although the $E S R$ decreases, there is substantial scatter in the data and a thus poor correlation.

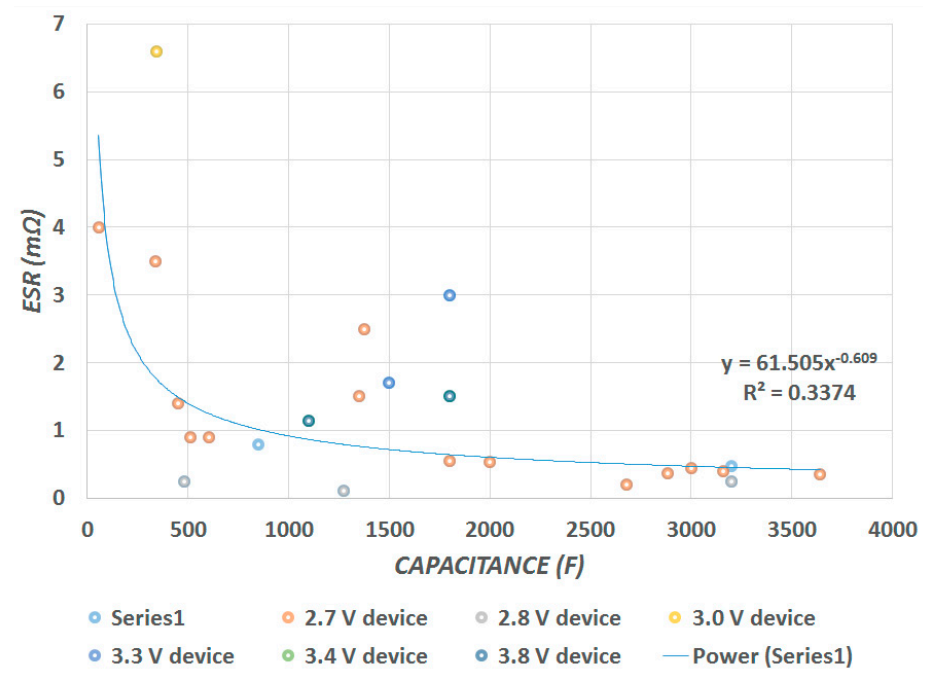

Figure 4. Equivalent series resistance vs. capacitance, $E S R \propto\left(\operatorname{cap}^{0.609}\right)^{-1}$.

$E S R$ is defined as $E S R=D / 2 \pi f_{C}=D \times X_{C}$, where $D$ is the dissipation factor (the dissipation factor varies with higher frequencies). The inverse of the quality factor $Q$ is the dissipation factor $D=\tan \delta$. Thus, a higher ESR indicates more capacitive losses i.e., more power dissipation. The capacitive reactance $X_{C}$ is defined as $1 /\left(2 \pi f_{C}\right)$. The capacitor impedance $Z$ is defined as $Z=\sqrt{(E S R)^{2}+\left(E S L-X_{C}\right)^{2}}$, where the ESL is the equivalent series inductance, and is expressed as $E S L=2 \pi f L$. Various dielectrics have different $E S R$ values. Hence, ESR can be reduced by using other dielectric materials. Considering the capacitive reactance of $E S R$ as well as the $\mathrm{R}_{\mathrm{p}}$ impedance magnitudes, the reactance is inversely proportional to the capacitance. Thus, a smaller $C$ produces larger reactance, implying more $\mathrm{R}_{\mathrm{P}}$ effect than $E S R$. For a larger $C, E S R$ has a greater significance than $R_{p}$, hence the appropriateness of a series circuit topology.

\section{Time Constant}

Several methods have been used to measure the capacitance of EDLCs, of which charge and discharging methods are common. The charge method is based on $C=t / R$. Similarly, in the discharge method the estimated capacitance is based on the discharge cycle in lieu of the charging cycle. Figure 5 shows the time constant increasing with energy. This can be attributed to the time it takes for the ion electrolyte to reach the highly porous carbon surface area. Hence, the time constant is dependent on the SCs' material employed in the manufacturing process. Each manufacturer has a proprietary recipe for parts, material, and manufacturing method used.

The amount of stored energy is computed by measuring voltage. The capacitor DC charge/discharge time $\left(t_{\text {disch }}\right)$ is related to the $\mathrm{V}_{\mathrm{ac}}$ fundamental frequency $\left(\mathrm{f}_{\mathrm{ac}}\right)$ by $t_{\text {disch }}>0.25 \times \mathrm{f}_{\mathrm{ac}}$. Supercapacitors exhibit large capacitance values such that traditional instrumentation cannot be utilized. Hence, an industry standard is to charge the capacitor for $30 \mathrm{~min}$ at rated voltage, and then discharge it via a constant current load. The discharge rate is approximately $1.0 \mathrm{~mA} / \mathrm{F}$ [1,7]; the drop-in potentials are measured, in addition to the required discharge time. Due to SCs' low cell voltage of $(1.0 \mathrm{~V}-3.4 \mathrm{~V})$, a series connection of SC cells is necessary to obtain the required higher voltage. However, unbalanced cell voltage distribution affects the cell performance and lifetime. As each SC 
will exhibit different levels of capacitance and resistance, it is essential for an SC to be balanced against exceeding its rated voltage.

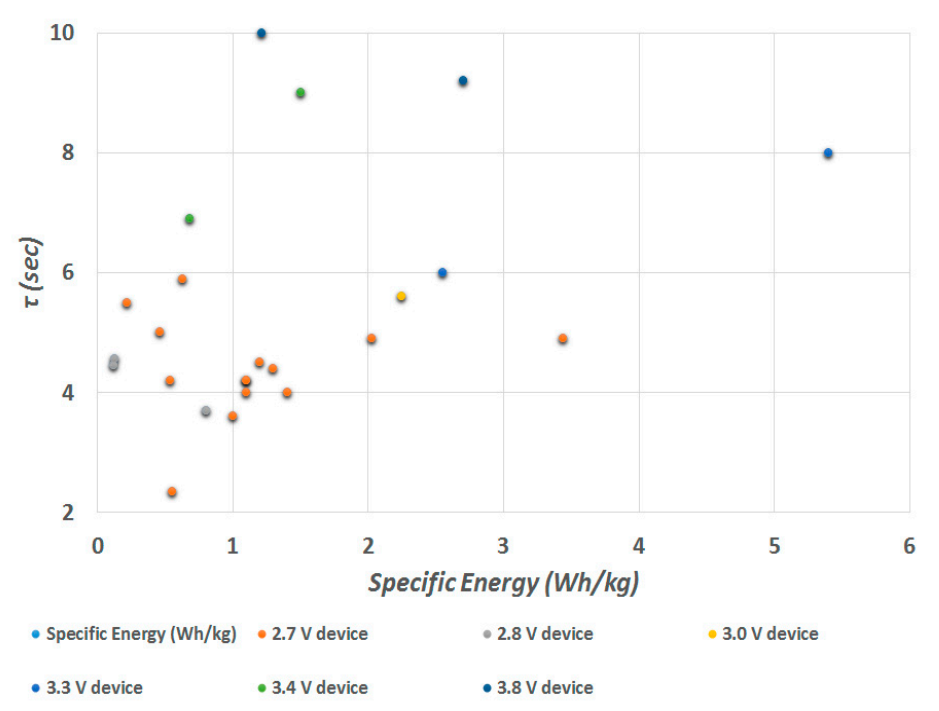

Figure 5. Tau increasing with specific energy.

\section{Efficiency}

SCs' charge-discharge cycle efficiency relies heavily on electrode conductivity. Charging is in the order of $10 \mathrm{~s}$, causing a shift from an unorderly discharged state into an orderly state where carbon pores absorb the ions. SCs are not as volumetrically efficient as batteries. However, their coulombic efficiency is greater than $99 \%$, even at very high currents, implying that little charge is lost when charging-discharging an SC [26,27]. Their main obstacle is maximizing cell capacitance while reducing the ESR, which enhances power performance, i.e., allows them to deliver and absorb a very high current. They are perfect devices for applications with fluctuating loads that require backup power, regenerative power, burst power, and fast charge. Unlike batteries, which maintain constant voltage, SCs experience voltage variations with current flow. They can withstand intense charge-discharge cycles due to the accumulated energy in the double-layers.

\section{Frequency Response}

In terms of frequency response, SCs are large power density energy storage devices. Their capacity is due to a complex internal structure that has a major impact on the SCs' dynamic behavior. Some researchers have stated that carbon nanotube-based SCs have attained a frequency of about $100 \mathrm{~Hz}$, and a power density over $8 \mathrm{~kW} / \mathrm{kg}$ [28,29], implying that maximal capacitance is available at low frequencies $(<100 \mathrm{~Hz})$. This indicates a better frequency response i.e., a better power performance specifically for low frequency filtering device applications. SC characteristics have strong frequency dependence, due the high porosity of the material used. Temperature has also a key impact on SC performance. The high specific area produced by high porosity is responsible for the decrease in capacitance with increasing frequency. Specific power related to capacitance density is shown in Figure 6 . There is a wide range of specific power achievable with a slight trend of higher specific power for devices with higher capacitive density.

Various research papers have covered different RC models to explain the SC performance [30]. However, such models are suited only for a limited range of frequencies. A better approach is to use higher order circuit models, which give accurate modeling results over a wider range of frequencies [31]. However, to cover a wider range of frequencies, the devices' intrinsic nonlinearities have to be considered. The frequency dependence arises from the different transit times of ions penetrating the carbon pore sizes [32]. The SC time constant is higher than that of typical electrolytic capacitors. Thus, 
exposing the device to continuous ripple current causes it to overheat. The capacitance drops off with frequency, which is related to the response time needed for the electrode-charged ions to ferry between positive and negative during charge and discharge. The dip in resistance is typical of the response time of the various resistive elements within the device. At low frequency, all resistive elements are present, whereas at high frequency only fast response elements such as contact resistance are present.

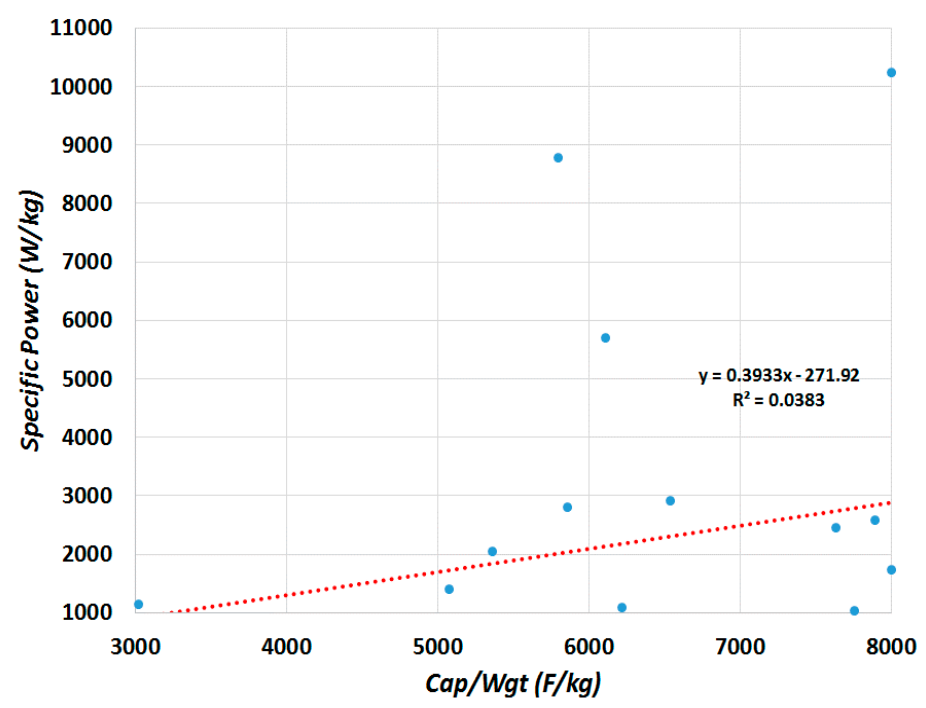

Figure 6. Specific power vs. specific capacitance (W/F) showing the power increasing slightly with the capacitance due to lower losses for bigger capacitors which have small ESRs due to packaging.

High surface area carbons are predominant materials in electrochemical double-layer capacitors (EDLCs). EDLCs do not have a conventional dielectric. However, the electrodes are designed to prevent ions recombination. The two electrodes are electrically coupled to their terminals via a metallic foil collector. EDLC volumetric capacitance is almost $10^{6}-10^{8}$ that of similar size electrolytic capacitor [32].

Conversely, EDLC low ESR creates an extremely high power density device. The electrodes are carbon activated material, which is conductive, and have a very large surface area to increase the capacitance. The charge distance separation in a double-layer is on the order of a few Ångströms $(0.3-0.8 \mathrm{~nm})$, and is static in origin [33]. Due to non-faradaic processes, EDLCs charge storage is extremely reversible, which lets them achieve high cycling stabilities. The electrodes are separated by a membrane to prevent short circuiting between the electrodes. The conductive Helmholtz double-layer sustains low voltages only, implying higher voltages are realized by matched series-connected EDLCs, similarly to series-connected batteries.

The composite is spun into the desired geometry and packed into aluminum (Al) housing. Typically, the cell is impregnated with a liquid, viscous, or solid-state electrolyte. The electrolyte depends on the power requirement, the operating voltage, and the temperature operating range. The outer housing is hermetically sealed. Higher energy densities can be achieved by enhancing the electrode capacitance, which can be reached via high capacitance electrode materials. This induced the exploration of alternate electrode materials, such as nanocomposite materials, to increase the capacitance by using nanoscale systems, or faster electronic and ionic transport characteristics [34,35].

\section{Economies of Scale}

Lowering the price of SCs is a vital step in realizing high future market penetration. It is not uncommon to speak of SC price in terms of cents per Farad ( $\not / F)$. SC cost depends on material and production costs. High purity carbon used in SCs cost about $\$ 70 / \mathrm{kg}$, making SCs competitive in terms of $\$ / \mathrm{kW}$. There is enormous potential for low-cost advanced power storage. It has only been a few 
years since SCs have been considered in the energy storage business. It thus represents a rising energy storage solution that bridges the gap between traditional capacitors and rechargeable batteries.

The main material inside SCs is active carbon, with the standard grade today providing a capacitance of $100 \mathrm{~F} / \mathrm{g}$ and costing about $\$ 28 / \mathrm{kg}$ [36]. It is expected that cell prices will steadily decline, and material advances will translate to a price of $\$ 0.0082 / \mathrm{F}$ in 2018 , in part to gradual performance improvements and manufacturing efficiency gains. High-voltage operation at $3.5 \mathrm{~V}$ will no doubt lower cell prices further. Graphene and nanostructured carbons offer higher capacity. The SC global market was estimated at $\$ 470$ million in 2010, reached $\$ 1.2$ billion in 2015 , and their demand is expected continuously double over the coming years. It is anticipated that the SC storage systems market will grow to $\$ 5.0$ billion [37] in 2025. Although a number of companies are developing SCs, the principle competitors are Maxwell Technologies, Panasonic, NessCap, LS Mtron, and le groupe Bolloré.

The potential market for SCs used for memory protection in the electronic industry is around $\$ 1.34$ billion/year [16,38]. New possibilities include the portable electronic device market, the power quality market (distributed generation) [39,40], low-emission hybrid cars, buses, and trucks. This growth is attributed to the need to bridge the gap between traditional capacitors and batteries regarding power performance. For SCs to be economically feasible for mass storage, energy densities must be higher in order to obtain fast discharge and a lower cost. High power standard capacitors are capable of fast discharge, but they lack the energy density of SCs. SCs are eco-friendly, lead $(\mathrm{Pb})$-free, Restriction of Hazardous Substances (RoHS)-compliant, and have no disposal issues at end of their lifecycle.

The most significant costly components of SCs are the active electrodes, electrolyte, and separator. The majority of commercial electrodes are bulk carbon with macropores leading to micropores. The best enhanced energy density experimental results for battery replacement and time constant for electrolytic capacitor replacement are exohedral. This implies nanostructure-carbon allotropes such as graphene and carbon nanotubes. Graphene has been shown to have some promising benefits, but it is uncertain whether it will prevail commercially. Large SCs are most likely to be used in electric vehicles, electric grids, railways, and other applications. For instance, they will eventually replace traction batteries in electric vehicles, and it is anticipated that they will replace inverter capacitors and be used in various electric vehicle (EV) applications such as regenerative braking and bus door opening. It is believed that the transportation sector represents the largest market opportunity for this device, mainly for engine starting-related applications, electrical system augmentation, braking energy recuperation, torque augmentation, burst power for idle stop-start processes, and hybrid electric drives for mass transit, trucks, and electric rail vehicles [41]. Numerous backup applications, including uninterruptible power supply, automated utility meters in smart grids, and wind turbine blade pitch systems, also represent a significant market opportunity.

Design enhancements, low-cost assembly, and increased sales volume have all contributed to the improvement of the manufacturing cost structure in recent years. It is anticipated that research and development investments will increase as the industry focuses on material science (graphene usage as a commercial-scale electrode material i.e., ElectroGraph) as well as new product design and development. Future energy trends indicate that they will become the power storage device of choice. Currently, they are emerging as an enabler in fuel efficient transportation.

\section{Conclusions}

SCs offer a promising alternative source to batteries in order to satisfy the demands of energy storage systems. They are reliable and best suited for high-power shuttling applications, but it is prudent to couple them with batteries. Yet, the development of SCs offers growth potential since they respond to key market and social needs. SCs are eco-friendly, help conserve energy, and enhance systems performance. 
This paper summarizes the performance of commercially available SCs as energy enhancers and their optimal usage in the transportation sector. The paper also recaps the storage mechanisms, the used materials, and the device attributes of SCs. SC performance relies greatly on the material selected for the electrode, electrolyte, separator, and collector plate. Energy and power densities are correlated, and largely depend on the electrode material. The electrolytes are carefully chosen to reduce the SC internal resistance.

In addition to providing a brief overview of SC technology as it stands today, we also managed to consolidate the performance characteristics of available devices outside the laboratory environment. This included the evaluation of capacitance density, equivalent series resistance, and time constant. Contrary to expectations, equivalent series resistance decreases with device total capacitance and the time constant varies dramatically for the devices considered. The collected data is empirical by nature; however, presenting it collectively provides end users with a comparison of performance and an identification of overall trends. In essence, this paper is of practical value to researchers and practicing engineers when evaluating new devices.

Author Contributions: Mazen Yassine and Drazen Fabris conceived of the analysis; Mazen Yassine compiled the data, analyzes and interpreted the results; and all authors contributed to the writing of the paper.

Conflicts of Interest: The authors declare no conflicts of interest.

\section{References}

1. Halper, M.; Ellenbogen, J. Supercapacitors: A Brief Overview; MP 05W0000272, March 2006; Mitre Corporation: McLean, VA, USA, 2006.

2. Electrical Engineering Portal, "Supercapacitors-Different than Others (Part 1)". Available online: http:/ / electrical-engineering-portal.com/super-capacitors-different-then-others-part-1 (accessed on 30 August 2016).

3. Electrical Engineering Portal, "Supercapacitors-Different than Others (Part 2)". Available online: http:/ / electrical-engineering-portal.com/super-capacitors-different-then-others-part-2 (accessed on 30 August 2016).

4. Rufer, A.; Barrade, P. A supercapacitor-based energy-storage system for elevators with soft commutated interface. IEEE Trans. Ind. Appl. 2002, 38, 1151-1159. [CrossRef]

5. Abbey, C.; Joos, G. Supercapacitor Energy Storage for Wind Energy Applications. IEEE Trans. Ind. Appl. 2007, 43, 769-776. [CrossRef]

6. Brownson, D.; Kampouris, D.; Banks, C.E. An overview of graphene in energy production \& storage applications. J. Power Sources 2011, 196, 4873-4885.

7. Cultura, A.B.; Salameh, Z.M. Performance evaluation of a supercapacitor module for energy storage applications. In Proceedings of the 2008 IEEE Power \& Energy Society General Meeting-Conversion \& Delivery of Electrical Energy in the 21st Century, Pittsburgh, PA, USA, 20-24 July 2008; pp. 1-7.

8. Anwar, A.; Ali, M.; Dougal, R. Supercapacitor energy storage for low-voltage ride through in a $13.8 \mathrm{KV}$ AC system. In Proceedings of the IEEE SoutheastCon, Concord, NC, USA, 18-21 March 2010; pp. 189-192.

9. Barrade, P.; Rufer, A. Current Capability \& Power Density of Supercacitors: Considerations on Energy Efficiency. In Proceedings of the EPE 2003: European Conference on Power Electronics and Applications, Toulouse, France, 2-4 September 2003.

10. Becker, H. Low Voltage Electrolytic Capacitor. U.S. Patent 2,800,616A, 23 July 1957.

11. Rightmire, R. Electrical Energy Storage Apparatus. U.S. Patent 3,288,641A, 29 November 1966.

12. Maxwell Technologies, Inc. Top 10 Reasons for Using Ultracapacitors in Your System Designs; Maxwell Technologies, Inc.: San Diego, CA, USA. Available online: http:/ /www.maxwell.com/images/documents/ whitepaper_top_10_reasons_for_ultracaps.pdf (accessed on 5 July 2016).

13. Conway, B. Electrochemical Supercapacitors: Scientific Fundamentals E Technological Applications; Kluwer Academic/Plenum Publishers: New York, NY, USA, 1999.

14. Signorelli, R.; Ku, C.; Kassakian, G.; Schindall, E. Electrochemical Double-Layer Capacitors Using Carbon Nanotube Electrode Structures. Proc. IEEE 2009, 97, 1837-1847. [CrossRef]

15. Christen, T.; Carlen, M. Theory of Ragone plots. J. Power Sources 2000, 91, 210-216. [CrossRef] 
16. Gidwani, M.; Bhagwani, A.; Rohra, N. Ultracapacitors: The near Future of Batteries. Int. J. Eng. Invent. 2014, 4, 22-27.

17. Hermann, V.; Schneuwly, A.; Gallay, R. High performance double-layer capacitor for power electronic applications. In Proceedings of the Power Conversion and Intelligent Motion (PCIM), Nürnberg, Germany, 19-21 June 2001.

18. Scherson, D.; Palencsár, A. Batteries \& Electrochemical Capacitors. Interface 2006, 15, 17-22.

19. IDTechEx. Batteries, Supercapacitors, Alternative Storage for Portable Devices 2009-2019; IDTechEx: Cambridge, UK, 2010.

20. Caob, Z.; Wei, B. A perspective: Carbon nanotube macro-films for energy storage. Energy Environ. Sci. 2013, $6,3183$.

21. Han, J.; Zhang, L.; Lee, S.; Oh, J.; Lee, K.; Potts, J.; Ji, J.; Zhao, X.; Ruoff, R.; Park, S. Generation of B-Doped Graphene Nanoplatelets Using a Solution Process \& Their Supercapacitor Applications. ACS Nano 2013, 7, 19-26. [PubMed]

22. Jampani, H.; Manivannan, A.; Kumta, P. Advancing the supercapacitor materials \& technology frontier for improving power quality. Electrochem. Soc. Interface 2010, 19, 57-62.

23. Yu, G.; Xing, X.; Pan, L.; Bao, Z.; Cui, Y. Hybrid nanostructured materials for high-performance electrochemical capacitors. Nano Energy 2013, 2, 213-234. [CrossRef]

24. Gebbia, M. Low ESR Capacitors: Fact or Fiction? Electron. Compon. News (ECN) 2001, 45, 95.

25. General Atomics, Inc. Engineering Bulletins Capacitors: Capacitors; General Atomics, Inc.: San Diego, CA, USA. Available online: https:/ / zh.scribd.com/document/88377370/Capacitor-Engineering-Bulletins (accessed on 27 November 2015).

26. Jayalakshmi, M.; Balasubramanian, K. Simple Capacitors to Supercapacitors-An Overview. Int. J. Electrochem. Sci. 2008, 3, 1196-1217.

27. Kurzweil, P.; Hildebrand, A.; Weiß, M. Accelerated Life Testing of Double-Layer Capacitors: Reliability \& Safety under Excess Voltage \& Temperature. ChemElectroChem 2015, 2, 150-159. [CrossRef]

28. Torregrossa, D.; Bahramipanah, M.; Namor, E.; Cherkaoui, R. Improvement of Dynamic Modeling of Supercapacitor by Residual Charge Effect Estimation. IEEE Trans. Ind. Electron. 2014, 61, 1345-1354. [CrossRef]

29. Fărcaş, C.; Petreuş, D.; Ciocan, I.; Palaghiţă, N. Modeling \& simulation of supercapacitors. In Proceedings of the 2009 15th International Symposium for Design \& Technology of Electronics Packages (SIITME), Gyula, Hungary, 17-20 September 2009; pp. 195-200.

30. Weddell, S.; Merrett, V.; Kazmierski, J.; Al-Hashimi, M. Accurate Supercapacitor Modeling for Energy Harvesting Wireless Sensor Nodes. IEEE Trans. Circuits Syst. II Express Briefs 2011, 58, 911-915. [CrossRef]

31. Dzielinski, A.; Sierociuk, D.; Sarwas, G.; Petras, I.; Podlubny, I.; Skovranek, T. Identification of the Fractional-Order Systems: A Frequency Domain Approach. Acta Montan. Slov. 2011, 1, $26-33$.

32. Schneuwly, A.A.; Sartorelli, G.; Auer, J.; Maher, B. Ultracapacitor in Applications in the Power Electronic World; White Paper; Maxwell Technologies, Inc.: San Diego, CA, USA. Available online: https:/ / www.tecategroup. com/white_papers/200904_WhitePaper_PowerElectronicApps.pdf (accessed on 6 April 2016).

33. Holmberg, S.; Perebikovsky, A.; Kulinsky, L.; Madou, M. 3-D Micro \& Nano Technologies for Improvements in Electrochemical Power Devices. Micromachines 2013, 5, 171-203.

34. Schindall, J. The Charge of the Ultracapacitors. IEEE Spectrum 2007, 44, 42-46. [CrossRef]

35. Shaw, D.G.; Cichanowski, S.W.; Yializis, A. A Changing Capacitor Technology-Failure Mechanisms \& Design Innovations. IEEE Trans. Electr. Insul. 1981, EI-16, 399-413.

36. U.S. Department of Energy. Grid Energy Storage; U.S. Department of Energy: Washington, DC, USA, 2013.

37. Lux Research, Inc. News \& Events, Market for Supercapacitors; Lux Research, Inc.: Boston, MA, USA. Available online: http:/ / www.luxresearchinc.com/news-and-events/press-releases/read/market-supercapacitorsgrow-128-836-million-2018 (accessed on 11 May 2016).

38. BCC Research. Technology Developments E Global Markets, Supercapacitors: EGY068A; BCC Research: Wellesley, MA, USA, 2011.

39. U.S. Securities \& Exchange Commission. File \# 001-15477; U.S. Securities \& Exchange Commission: Washington, DC, USA. Available online: https://www.sec.gov/Archives/edgar/data/319815/000031981516000099 (accessed on 21 February 2017). 
40. Tecate Group. What Is an Ultracapacitor; Tecate Group: San Diego, CA, USA. Available online: https: //www.tecategroup.com/app_notes/0_Tecate_Group_What\%20is\%20an\%20ultracapacitor.pdf (accessed on 3 December 2015).

41. Todd, R.; Wu, D.; Girio, S.; Poucand, M.; Forsyth, A. Supercapacitor-based energy management for future aircraft systems. In Proceedings of the IEEE Applied Power Electronics Conference \& Exposition (APEC), Palm Springs, CA, USA, 21-25 February 2010; pp. 1306-1312. 